\title{
Is prone free breathing better than supine deep inspiration breath-hold for left whole-breast radiotherapy? A dosimetric analysis
}

\author{
Xinzhuo Wang ${ }^{1,2}$ - Odile Fargier-Bochaton ${ }^{2}$ Giovanna Dipasquale ${ }^{2}$ Mohamed Laouiti ${ }^{2,3} \cdot$ \\ Melpomeni Kountouri ${ }^{2}$. Olena Gorobets ${ }^{4}$ (D) $\cdot$ Nam P. Nguyen $^{5} \cdot$ Raymond Miralbell $^{2,6,7}$ (D) \\ Vincent Vinh-Hung ${ }^{2,4}$ (D)
}

Received: 20 June 2020 / Accepted: 16 November 2020 / Published online: 8 January 2021

(c) The Author(s) 2021

\begin{abstract}
Purpose The advantage of prone setup compared with supine for left-breast radiotherapy is controversial. We evaluate the dosimetric gain of prone setup and aim to identify predictors of the gain.

Methods Left-sided breast cancer patients who had dual computed tomography (CT) planning in prone free breathing (FB) and supine deep inspiration breath-hold ( $\mathrm{DiBH})$ were retrospectively identified. Radiation doses to heart, lungs, breasts, and tumor bed were evaluated using the recently developed mean absolute dose deviation (MADD). MADD measures how widely the dose delivered to a structure deviates from a reference dose specified for the structure. A penalty score was computed for every treatment plan as a weighted sum of the MADDs normalized to the breast prescribed dose. Changes in penalty scores when switching from supine to prone were assessed by paired $t$-tests and by the number of patients with a reduction of the penalty score (i.e., gain). Robust linear regression and fractional polynomials were used to correlate patients' characteristics and their respective penalty scores.

Results Among 116 patients identified with dual CT planning, the prone setup, compared with supine, was associated with a dosimetric gain in $72(62.1 \%, 95 \%$ CI: 52.6-70.9\%). The most significant predictors of a gain with the prone setup were the breast depth prone/supine ratio $(>1.6)$, breast depth difference $(>31 \mathrm{~mm})$, prone breast depth $(>77 \mathrm{~mm})$, and breast volume $(>282 \mathrm{~mL})$.

Conclusion Prone compared with supine DiBH was associated with a dosimetric gain in $62.1 \%$ of our left-sided breast cancer patients. High pendulousness and moderately large breast predicted for the gain.
\end{abstract}

Keywords Linear models $\cdot$ Cardiotoxicity prevention $\cdot$ Radiation dosage $\cdot$ Mean absolute dose deviation $\cdot$ Weighted excess dose deviation score $\cdot$ Dose volume histogram

Trial registration Trial registration number ClinicalTrials.gov NCT02237469, September 11, 2014; retrospectively registered.

Availability of data and material Patients' data are available on Mendeley, Reserved https://doi.org/10.17632/vftzc2r746.1. Link to preview: https://data.mendeley.com/datasets/vftzc2r746/draft? $\mathrm{a}=873 \mathrm{c} 03 \mathrm{~d} 8-1 \mathrm{ffa}-4310-\mathrm{b} 36 \mathrm{f}-88 \mathrm{adc} 5 \mathrm{ead} 4 \mathrm{dd}$.

\section{Code availability Software application available on https://cran.r-} project.org/.

Raymond Miralbell

raymond.miralbell@unige.ch

Vincent Vinh-Hung, MD, PhD

vh@onco.be
1 Radiation Oncology, Tianjin Union Medical Center, 300121 Tianjin, China

2 Radiation Oncology Department, Geneva University Hospital, Geneva, Switzerland

3 Service de radio-oncologie, Hôpital Riviera-Chablais, Rennaz, Switzerland

4 CHU de Martinique, Fort-de-France, Martinique, France

5 Howard University, Washington DC, USA

6 Proton Therapy Centre, Quirónsalud, Madrid, Spain

7 Institut Oncològic Teknon (IOT), Barcelona, Spain 


\section{Introduction}

Breast cancer is the most commonly diagnosed cancer and the leading cause of cancer death in women worldwide [1]. Death rates have been stable so far or slightly declining in some countries [2,3], which may reflect early detection and/or improved treatment. In order to further improve survival and to reduce the risk of treatment sequelae, more clinical research is needed. Randomized trials have shown the importance of radiotherapy for optimal local control of breast cancer [4]. Yet, despite a $67 \%$ reduction in local recurrence rates, the survival benefit for those patients treated with postoperative radiotherapy has been disproportionately modest [4]. There has been concern that local control is offset by an increased risk of heart, vascular, and lung toxicity [5-14]. For decades, one of the major challenges facing radiation oncologists has been to reduce the risk of toxicity without decreasing the chances of cancer control and survival [10]. A good number of technical procedures seeking to find the best trade-off between side effects and tumor control are actively pursued [15-20]. This subject matter is even more relevant when considering treatment optimization for left-sided breast cancer [21-28]. A prone setup has been advocated to spare the left lung and the heart when irradiating such patients. However, most published studies addressing this question have limited their scope to large breasts only [26, 29] (mean $896 \mathrm{~mL}$ in an on-going review of 21 studies 2007-2015, V. Vinh-Hung). With a prone setup, the breast sags from the chest wall, allowing tangential fields to avoid the heart and the left lung. However, the dose to the heart might increase due to movement of the heart anteriorly in the prone position [30]. The dosimetric implications of prone positioning therefore will depend on the location of the breast target tissues relatively to the heart and chest wall [31].

Considering the variability of anatomic characteristics, organ displacement, and postsurgical changes, one may need customized planning comparisons to be able to select between prone and supine for every patient. Drawbacks are two computed tomography (CT) simulations and twice the dosimetry, the dose burden of double CT exposure to the patients, and an increased workload for oncologists and dosimetrists [32-34]. Clinical tools are needed to determine beforehand which position would be most advantageous.

Since 2010 through 2013, dual planning has been applied in our institution for most patients who had been referred for adjuvant radiotherapy after conservative surgery. In the present study, we evaluated left-sided breast cancer patients simulated both prone in free breathing and supine under deep inspiration breath-hold (DiBH) conditions. We aimed to investigate whether a change in the treatment position setup from supine to prone was associated with a dosimetric gain for these left-breast cancer patients, and to identify characteristics correlated with the gain.

\section{Materials and methods}

Patients were retrospectively retrieved from the Geneva University Hospital radiation oncology department database. We selected patients with left-sided breast cancer referred from September 2010 to August 2013 for adjuvant radiotherapy after conservative surgery with completely resected primary breast cancer. All selected patients underwent dual CT simulation and treatment planning, prone in free breathing and supine in $\mathrm{DiBH}$ conditions. Patients gave their written consent prior to simulation. Double CT simulation was not done if the patient expressed discomfort during the prone setup after giving their consent. The study received institutional review board approval and was registered under ClinicalTrials.gov Identifier NCT02237469.

In the supine setup patients were positioned on an inclined breast board with arms extended over the head [35, 36]. For the prone setup patients were positioned using the Bionix Prone Breast System (Bionix Development Corporation, Toledo, OH, USA) (2010-2012) and the Varian Pivotal Prone Breast Care (Varian Biomedical Systems, Palo Alto, CA, USA) from 2013. Covering both lungs and breasts from the top of the lungs to $5 \mathrm{~cm}$ caudal to the breasts or to the base of the lungs, whichever was the most caudal, 3-mm thick CT slices without contrast were used. The right breast rested on a 5-degree foam wedge. The left breast was intended to hang centered and unhindered through the couch's opening. A patient self-assessed questionnaire recorded the patient's subjective feelings of pain, fear, anxiety, discomfort, and position preference at the end of simulation [37].

The breast clinical target volume (CTV) was contoured up to $1 \mathrm{~cm}$ below the sternoclavicular joint (cranially), to the farthest visible breast contour (caudally), to the perforating mammary vessels or to the edge of the sternum (medially), to the lateral breast-skin fold (laterally), to, but not beyond, the surface of the pectoralis muscle or ribs and intercostal muscles (posteriorly), and up to $5 \mathrm{~mm}$ under the skin surface (anteriorly) [38]. The tumor bed CTV was based on combined clinical, radiological, and surgical-pathological data. The planning target volume (PTV) equated to the CTV without expansion. Contouring the contralateral breast included the skin surface; contouring the heart included the pericardium and the exiting large vessels [39], but not above the top of the left atrium. Automatic segmentation contoured both the lungs and the body's external contour.

The dose prescription for most patients was $47.25 \mathrm{~Gy}$ to the breast in 21 fractions, 4 fractions/week [40]. Treatments were planned with tangential fields using the Varian Eclipse 


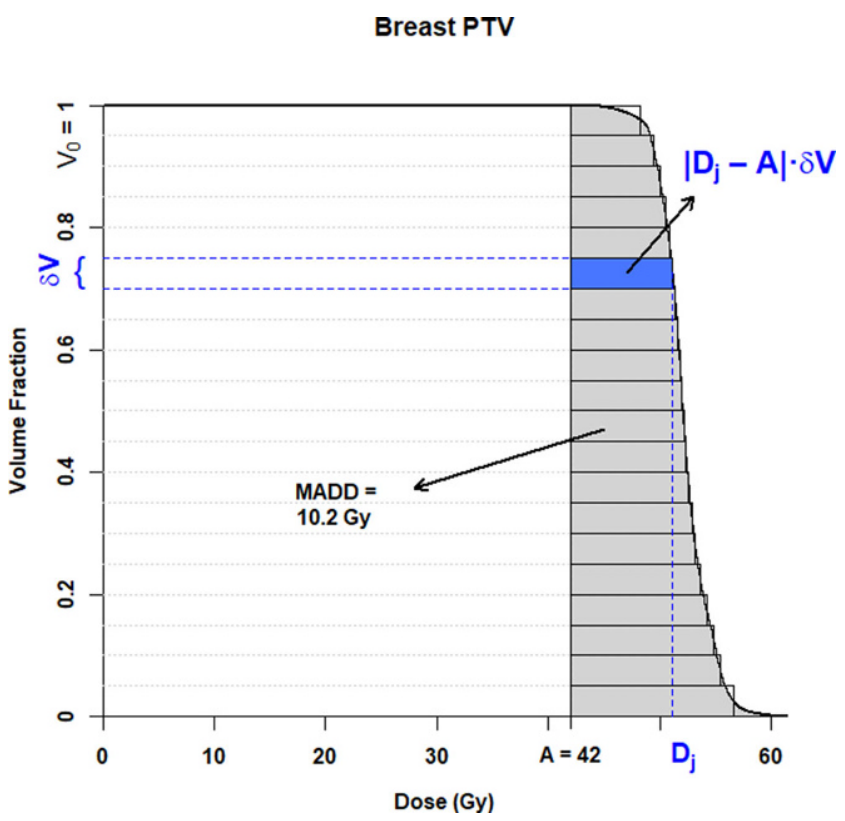

Fig. 1 Computation of the mean absolute dose deviation (MADD). Dose-volume histogram (DVH) of a fictive case prescribed $42 \mathrm{~Gy}$ to the breast planning target volume (PTV). The MADD is the grey shaded area between the DVH curve and the prescription dose, $A=42 \mathrm{~Gy}$. At each point $j$ of the DVH, the deviation is $\left|D_{j}-A\right|$. The deviation on a $\delta V$ volume interval is the horizontal rectangle between the curve and the reference, shaded blue at the instance of the dose $D_{j}$. The total grey area is approximated by the sum of the plain rectangles. If the DVH has been plotted with the volumes already scaled to 1 as in this figure, $V_{0}=1$, the area directly provides the MADD, otherwise the area needs to be divided by the structure's volume

treatment planning system with the prescription of $95 \%$ of the dose covering at least $95 \%$ of the breast PTV, covering $100 \%$ of the tumor bed, and the breast PTV $\mathrm{V}_{107 \%}<2 \mathrm{cc}$. Dose constraints to the organs at risk (OAR) were the following: ipsilateral lung $\mathrm{V}_{20 \mathrm{~Gy}}<10 \%$, heart near max $\mathrm{D}_{2 \%}$ $<15 \mathrm{~Gy}$, and heart mean dose $<3 \mathrm{~Gy}$. Beam arrangements were required to avoid the contralateral breast. The chest wall was excluded from the PTV. Planning implemented forward intensity-modulated radiotherapy [41], combining wedges, field-in-field compensation, and a mix of photon energies. Heart shielding was undertaken if necessary using a multileaf collimator [42]. All doses were converted to percent values of the prescribed dose.

A penalty score was built from the mean absolute dose deviation (MADD) [43]. The MADD of a structure measures how far the planning dose deviates from a given reference dose specified for the structure. Applying the notation $M_{i}$ as the MADD of structure $i, D$ the dose abscissa and $V$ the volume ordinate of the set of points representing the cumulative dose-volume histogram (DVH) curve of the structure, $V_{0}$ the volume of the structure, and $A$ the reference dose for the structure ( $D, V, V_{0}$, and $A$ subscript $i$ implicit), the MADD $M_{i}$ can be defined as

$M_{i}=\int_{0}^{V_{0}} \frac{|D-A|}{V_{0}} d V$

The equation represents the area between the DVH of the structure and the reference dose $A$, where $A$ is 0 for an OAR, or the prescribed dose for a PTV. Graphically, the MADD $M_{i}$ is a horizontal integration with respect to $V$. Computation can be implemented by rectangular strips (Fig. 1), by writing for a set of $n$ DVH datapoints

$M_{i}=\sum_{j=1}^{n} \frac{\left|D_{j}-A\right| \times \delta V}{V_{0}}$.

The difference $\left|D_{j}-A\right|$ is a difference between doses, $\delta V / V_{0}$ cancel out as unitless; hence, the MADD unit is the same as that used for the DVH, either in absolute or relative dose. The lowest theoretical $M_{i}$ value is 0 for a perfect dose distribution.

The penalty score pertaining to a patient's treatment plan was defined as a weighted sum of the MADDs:

Penalty Score $=\sum_{i} w_{i} \times M_{i}$

where $i$ represents a list of structures, $M_{i}$ represent the corresponding MADDs, and $w_{i}$ represent the weights attributed to the structures. Constraining the weights to sum to $1, \sum_{i} w_{i}=1$, allows expression of the penalty score on the same scale as the MADDs and the dose prescription. Unlike the homogeneity index which is a unitless ratio applicable only to target volumes, the penalty score so defined is interpretable as a weighted average of all OAR and PTV dose deviations.

The $w_{i}$ weights selected by first intention in this study were as follows: $0.40,0.16,0.14,0.11,0.10$, and 0.09 , for the heart, right lung, left lung, tumor bed, right breast, and left breast, respectively. That set of weights, which we call "penalty type 1 ," was chosen to represent the authors' practice for breast cancer when considered as low risk. The motivation stems from the legacy of studies that investigated the impact of breast radiotherapy on mortality [4-13]. A set of ordinal priorities was established assigning heart $>$ lungs $>$ CTV tumor bed $>$ contralateral breast $>$ CTV ipsilateral breast, which were then converted to the numerical weights. Other priority types will be discussed later as an expanded study.

The prone penalty scores were compared with the supine penalty scores. The prone setup was considered to provide a dosimetric gain if it reduced the penalty. The comparisons 
Fig. 2 Measurement of breast depth supine (a) and prone (b). The depth was measured on the CT slice through the nipple using an on-screen adjustable T-square ruler, recording the largest distance from the breast contour to the base set tangent to the pleura. If the breast point falls on the nipple, the measurement was performed flush with the areola
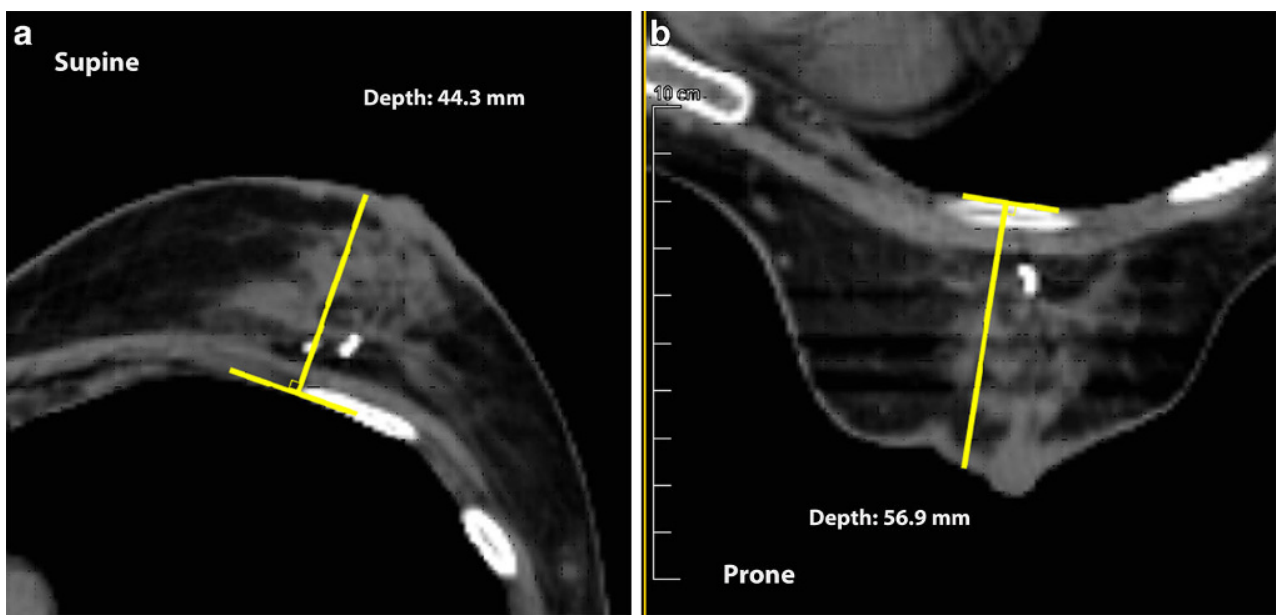

Fig. 3 Averaged cumulative dose-volume histograms by structure and setup. Volume y-axis square root scale. Dark grey: $99 \%$ confidence

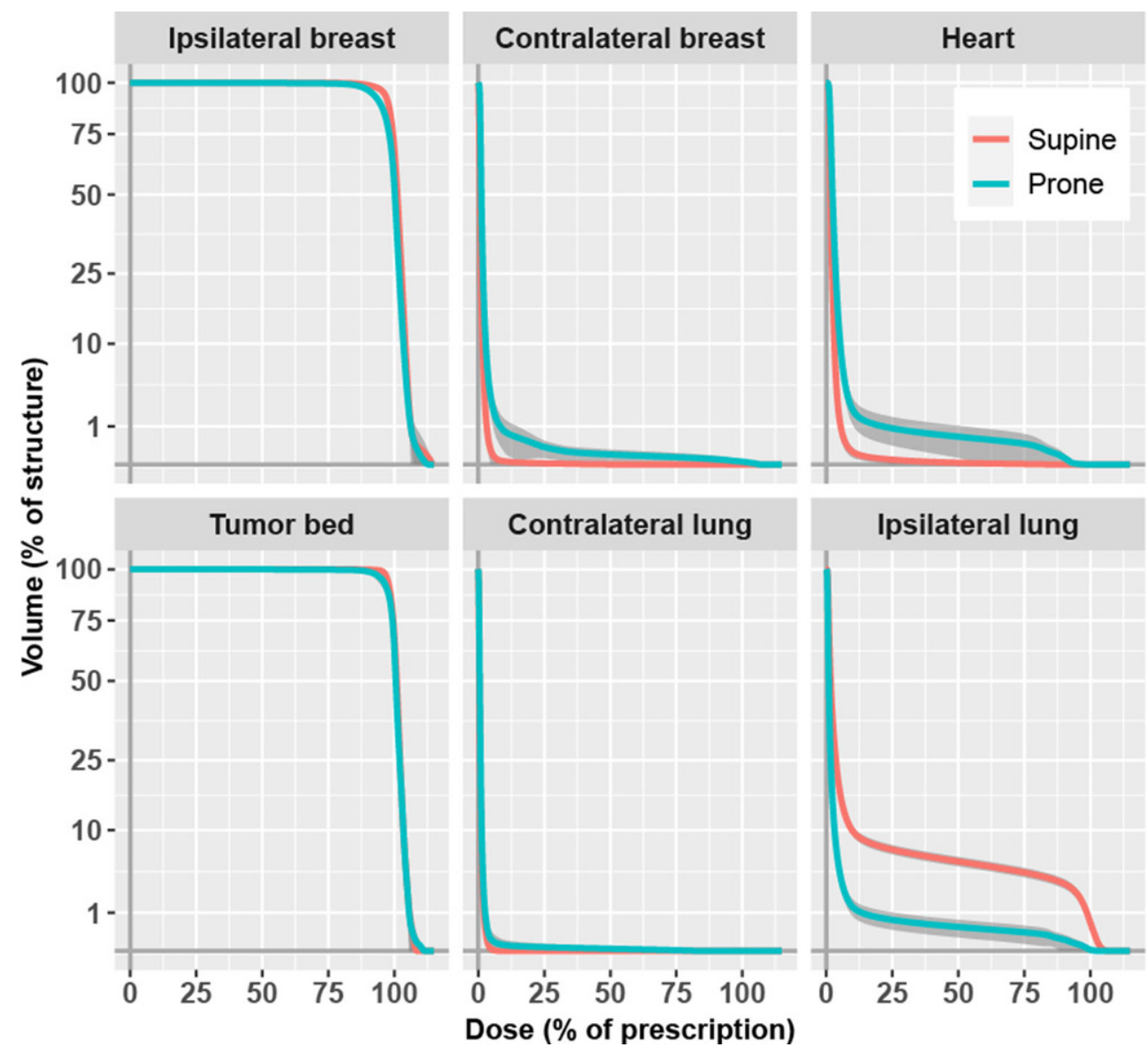

were performed using the following three assessments: by aggregate comparison of the mean penalty scores using a $t$ test [44]; by assessing the number of patients in whom the prone setup provided a reduction in the penalty score, and computing the proportion's confidence interval using the exact binomial test [45]; by visual comparison using a bullet-arrow graph that we designed as a generic tool to explore changes from a baseline. Briefly, the bullet-ar- row graph procedure is as follows: 1) the patients' supine penalty scores are sorted; 2) the sorted supine penalties are plotted as bullets; 3 ) the patients' prone penalties are plotted as arrowheads; 4) the bullet and arrowhead pairs are joined - the resulting arrow segments indicate the magnitude and the direction of the penalty changes.

Two regressions were applied to evaluate the pre-dosimetry patient characteristics as potential predictors of a dosi- 
Fig. 4 Mean absolute dose deviation (MADD) by structure and according to setup. MADD y-axis square root scale. Box: lower quartile, median, upper quartile. Whiskers: $1.5 \times$ interquartile range. Black dot: average of the MADDs. Color dots: outliers
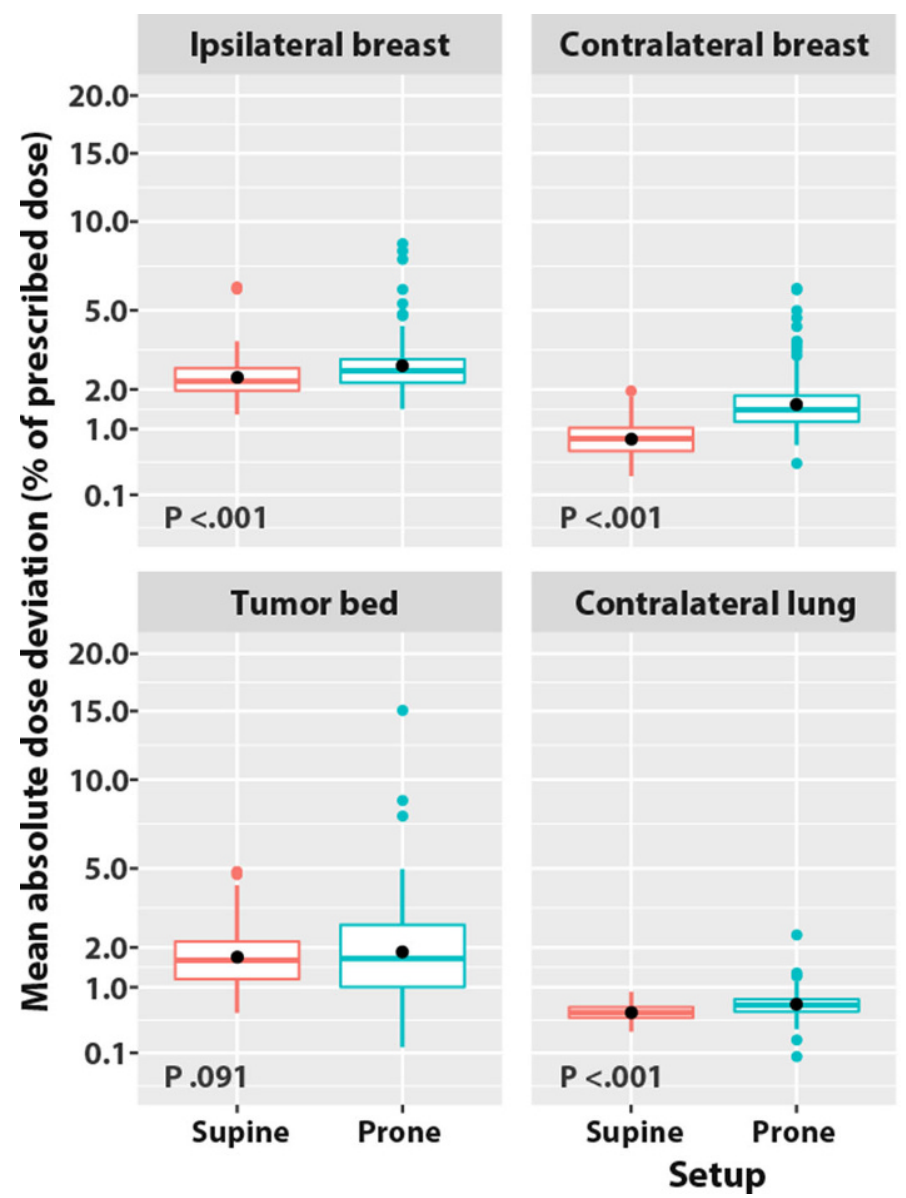
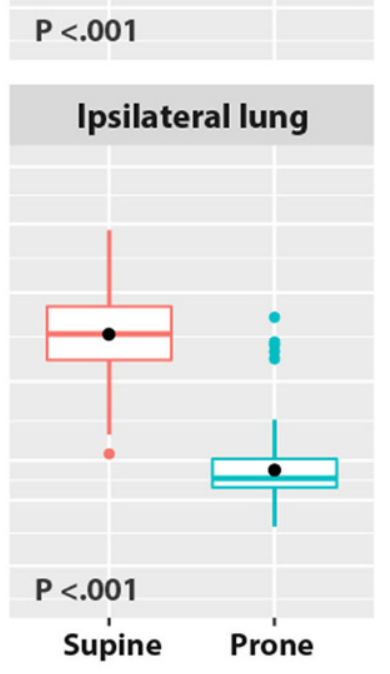

metric gain: fractional polynomial regression to assess nonlinearity [46], and robust linear regression [47] if linearity was acceptable. The patient characteristics evaluated were as follows: age, height, weight, body mass index (BMI), tumor location, breast volume, patient's setup preference, and CT-based distance between the left anterior descending coronary artery (LAD) and the chest wall [31], and the supine and prone breast depths (Fig. 2). Non-numeric characteristics were dummy binary coded as " 0 " for the reference and " 1 " for the other levels; regression measures the change in the response when the characteristic changes by one level [48]. The post-dosimetry values of the penalty scores were also assessed as additional predictors of the prone penalty score reduction.

All statistical computations used $\mathrm{R}$ version 3.6.3 [49]. The regressions were implemented using the package $\mathrm{mfp}$ with two degrees of freedom [46], and using function rlm of the package MASS [47]. Graphic displays used ggplot [50].

\section{Results}

We identified 299 dual prone-supine breast CT simulation cases. Three cases were excluded-one volumetric modulated arc therapy and two non-finalized prone planning. Of the remaining 296 dual plans, 151 were right-breast treatments, leaving a total of 145 left-breast cases to be assessed, 27 of whom were unable to hold breath on supine at CT and were not eligible; 2 were repeat CT after initial simulation and were excluded. Thus, the total study population was composed of 116 patients with dual planning at initial simulation. Those included 2 patients with breast implants and 3 with bilateral cancer who had separate planning for the left and right breasts.

The median age of the patients was 57.5 years, range 36-82 (Table 1), 4.5 years younger than US patients [2] but comparable to another registry data [12]. Overweight and obesity were frequent and represented $51.5 \%$ of the non-missing records. The left breast median volume supine was $484 \mathrm{~mL}$ (range 34-1580) comparable to the median volume prone of $477 \mathrm{~mL}$. The contralateral breast median volume supine was $597 \mathrm{~mL}$ (range 81-2138), prone $591 \mathrm{~mL}$ (range 88-1736). The patients preferred the supine setup in 
Fig. 5 Patients' prone penalty vs. supine penalty (type 1). Penalty score units are the percentages of the prescribed dose. Bullet (dot): supine penalty. Arrow: prone penalty. Red: the prone setup increases the penalty, blue: the prone setup decreases the penalty

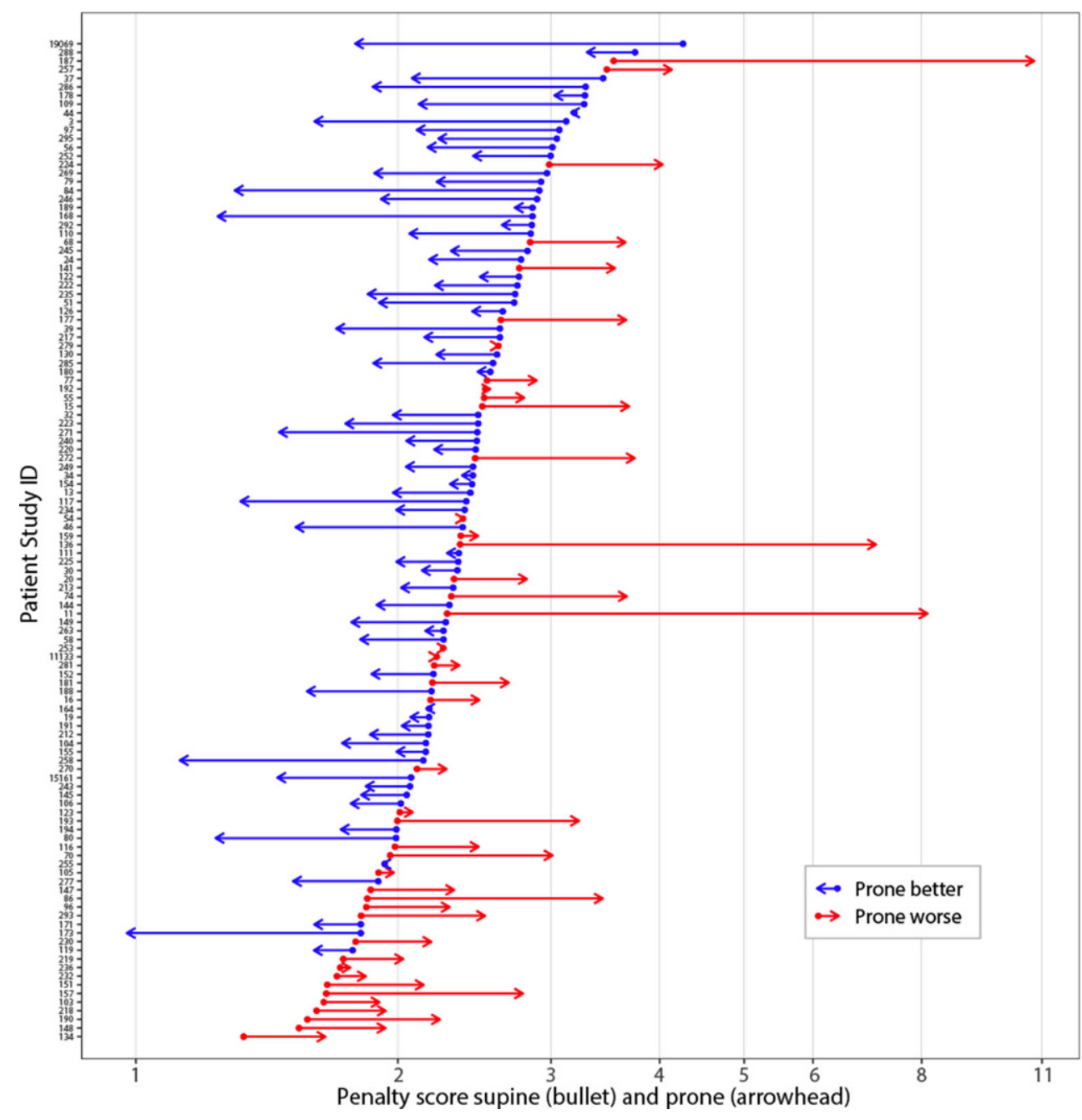

$52.6 \%$ of the cases, while $47.4 \%$ preferred prone or were indifferent.

Fig. 3 shows the cumulative DVHs of the six structures as the pointwise average for all 116 patients according to position setup. Compared to supine, the prone setup showed a small underdosage of the ipsilateral breast almost complying with the prescription dose, a higher dose to the contralateral breast, a higher dose to the heart, a slight underdosage to the tumor bed near the prescription dose, and a large reduction of the dose to the ipsilateral lung.

The corresponding MADDs for the prone vs. supine setup are displayed in Fig. 4. All $p$-values were $<0.001$, except for that of the tumor bed, $p=0.091$. The prone setup slightly increased (by a difference of $<0.5 \%$ of prescribed dose) the MADDs of the ipsilateral breast, the tumor bed, and the contralateral lung. The prone setup increased more notably (by a difference of $\geq 0.5 \%$ of prescribed dose) the MADD of the contralateral breast, $1.7 \%$ of prescribed dose vs. that of the supine setup at $0.8 \%$, and the MADD of the heart, $3.4 \%$ vs. $1.9 \%$ for the supine setup. The prone setup reduced the MADD of the ipsilateral lung by over two thirds, $1.9 \%$ vs. $7.6 \%$ for the supine setup.

Computation of the patients' type 1 penalty scores found a mean penalty of $2.39 \%$ of prescribed dose in the prone setup as compared with $2.41 \%$ in the supine setup (twosided $t$-test, $p=0.868)$. The median penalty score for prone was 2.14 (range 0.98-10.78), vs. 2.36 (range 1.33-4.26) for supine; the median penalty score change was -0.21 (range $-2.47-7.24)$.

Fig. 5 displays that the penalty score was reduced for prone in 72 patients out of $116(62.1 \%$, 95\% CI: $52.6 \%$, $70.9 \%$ ). The reduction was dependent on the value of the supine penalty: the prone setup reduced the penalty in 7 of 26 patients whose supine penalty was $<2(26.9 \% ; 95 \%$ CI: $11.6 \%, 47.8 \%$, lower third of Fig. 5) compared with a reduction in 65 of 90 patients whose supine penalty was $\geq 2$ (72.2\%; $95 \% \mathrm{CI}: 61.8 \%, 81.1 \%$; upper two thirds of Fig. 5), $p<0.001$.

Fig. 6a plots the penalty score differences $(\Delta$, prone minus supine) according to 12 selected characteristics. A positive $\mathrm{y}$-axis value indicates that the prone setup increased 


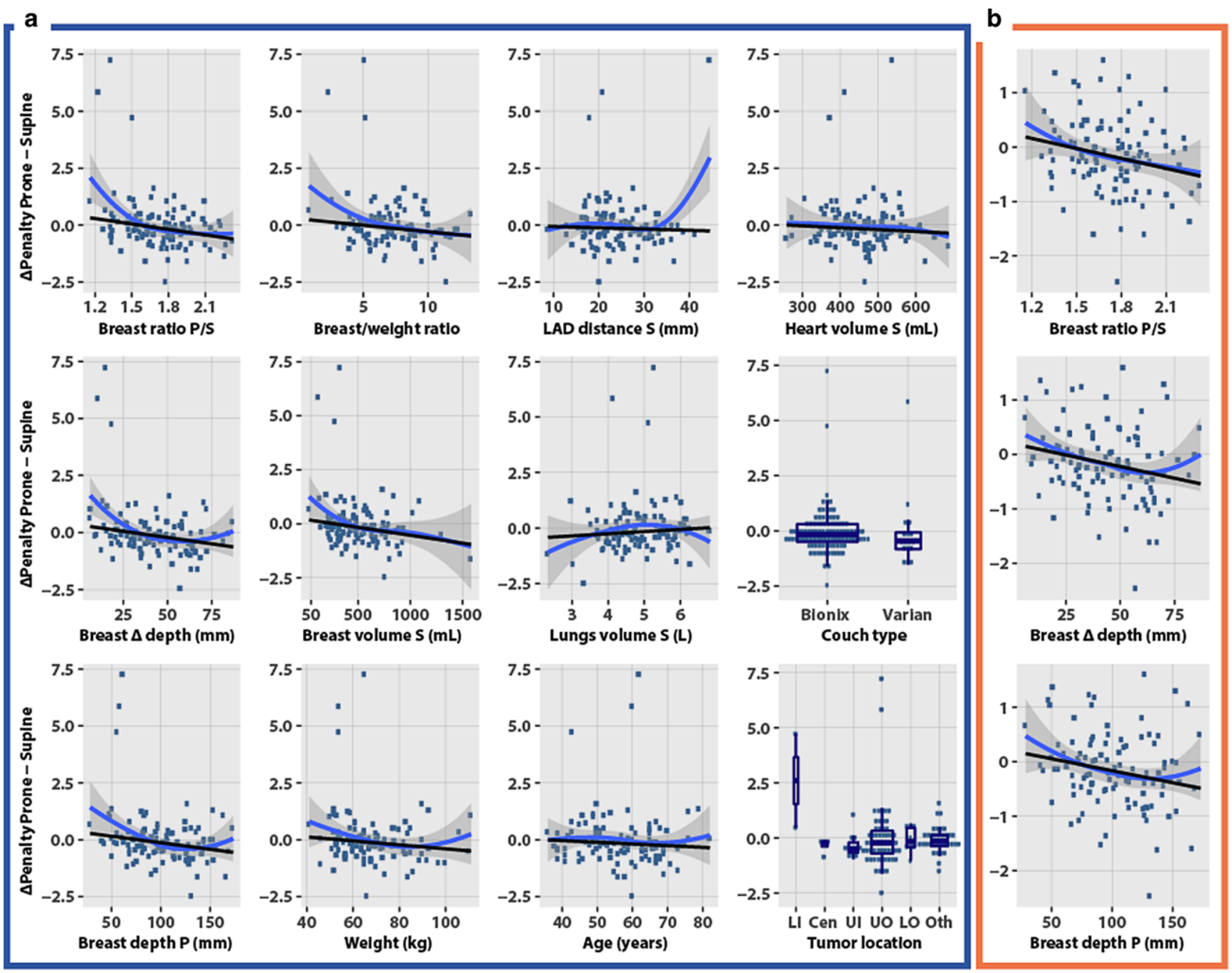

Fig. 6 Predictors of the penalty (type 1) difference between prone and supine setups. Y-axis, penalty score prone minus penalty score supine; positive, prone worse; negative, prone better. Blue curve: local polynomial smoothing and $95 \%$ confidence (descriptive); note the LAD curvature by a single outlier. Black line: robust linear regression. $P$ prone, $S$ supine, $L A D$ left anterior descending artery, $L I$ lower inner, $C e n$ central, $U I$ upper inner, $U O$ upper outer, $L O$ lower outer; $O$ th other. a All 116 cases. b Selected subplots excluding three outliers with $\Delta$ penalty $>2.5, N=113$

the penalty (prone worse) and a negative value indicates that prone reduced the penalty (prone better). Pendulousness indicators, breast ratio prone/supine, breast depth, breast $\Delta$ depth prone - supine difference, and weight were associated with decreased penalty scores in the prone setup. Age, heart volume, and LAD-chest wall distance showed no strong correlation with $\Delta$ penalty. Among the categorical characteristics, a trend favored the prone setup using the Varian couch. According to tumor location, the lower inner quadrant was associated with an increased prone penalty though this location was underrepresented with only 2 patients.

Three top outliers were apparent in the 12 subplots of Fig. 6a, corresponding to the 3 patients with the largest increase in the prone penalty in Fig. 5. Excluding these three outliers did not remarkably change the linear fit (Fig. 6b; only the first column of subplots is shown to avoid redundancy).

Table 2 based on the full patient data summarizes the models of dosimetric gain as a function of the patients' characteristics. All the characteristics related linearly with the dosimetric gain, except the breast depth ratio, the breast $\Delta$ depth difference, and the right breast volume for which fractional polynomial regression indicated a significant nonlinear functional form. Nonlinear transforms caused small differences in the estimates (Table 2 footnote). We retained only the linear regression models. The models were ranked into broad categories. The most significant pre-dosimetry predictors were the three indexes of breast pendulousness, the ratio of the breast volume to body weight, the lower inner quadrant tumor location, and the breast volume. Breast depth in supine setup and weight were borderline signifi- 
Table 1 Patient characteristics

\begin{tabular}{|c|c|c|c|}
\hline Characteristic & $N$ & Value & Percent \\
\hline$\overline{\text { Age (years) }}$ & 116 & - & - \\
\hline Median (range) & - & $57.5(36-82)$ & - \\
\hline Pathological stage & 116 & - & - \\
\hline 0 & - & 7 & 6.0 \\
\hline I & - & 69 & 59.5 \\
\hline II & - & 39 & 33.6 \\
\hline III & - & 1 & 0.9 \\
\hline$p T$ & 116 & - & - \\
\hline Tis & - & 7 & 6.0 \\
\hline $\mathrm{T} 1$ & - & 80 & 69.0 \\
\hline $\mathrm{T} 2$ & - & 28 & 24.1 \\
\hline $\mathrm{T} 3$ & - & 1 & 0.9 \\
\hline Lymph node ratio (fraction) & 114 & - & - \\
\hline Median (range) & - & $0(0-0.5)$ & - \\
\hline Body mass index $\left(\mathrm{kg} / \mathrm{m}^{2}\right)$ & 95 & - & - \\
\hline Median (range) & - & $25(17-43)$ & - \\
\hline Weight $(\mathrm{kg})$ & 107 & - & - \\
\hline Median (range) & - & $67(41-111)$ & - \\
\hline Tumor location & 116 & - & - \\
\hline Lower inner & - & 2 & 1.7 \\
\hline Central & - & 4 & 3.4 \\
\hline Upper inner & - & 11 & 9.5 \\
\hline Upper outer & - & 57 & 49.1 \\
\hline Lower outer & - & 8 & 6.9 \\
\hline Other & - & 34 & 29.3 \\
\hline Heart volume supine $(\mathrm{mL})$ & 116 & - & - \\
\hline Median (range) & - & $\begin{array}{l}461 \\
(259-687)\end{array}$ & - \\
\hline $\begin{array}{l}\text { Left breast volume supine } \\
(m L)\end{array}$ & - & - & - \\
\hline Median (range) & - & $\begin{array}{l}484 \\
(34-1580)\end{array}$ & - \\
\hline Couch type & 116 & - & - \\
\hline $\begin{array}{l}\text { Bionix (Bionix Development } \\
\text { Corporation, Toledo, } \mathrm{OH}, \\
\text { USA) }\end{array}$ & - & 99 & 85.3 \\
\hline $\begin{array}{l}\text { Varian (Varian Biomedical } \\
\text { Systems, Palo Alto, CA, } \\
\text { USA) }\end{array}$ & - & 17 & 14.7 \\
\hline Patient's preference & 78 & - & - \\
\hline Supine & - & 41 & 52.6 \\
\hline No preference & - & 14 & 17.9 \\
\hline Prone & - & 23 & 29.5 \\
\hline Treatment applied & 116 & - & - \\
\hline Supine & - & 71 & 61.2 \\
\hline Prone & - & 45 & 38.8 \\
\hline
\end{tabular}

$N$ number with the data available cant, $p=0.061$ and $p=0.063$, respectively. Quality indicators of $\mathrm{DiBH}$ such as larger lung volume expansion or LADto-chest wall distance, younger age, and patient's preference were not significant.

The models allow the extraction of the range of values for which a dosimetric gain with the prone setup might be predicted. Dividing the intercept with the coefficient provides the cutoff where the gain changes sign. Table 2 shows a reduction in the prone penalty at a breast depth ratio prone/supine $>1.6$, breast $\Delta$ depth $>31 \mathrm{~mm}$, breast depth prone $>77 \mathrm{~mm}$, left breast volume $>282 \mathrm{~mL}$, and right breast volume $>347 \mathrm{~mL}$. Regression excluding the three outliers showed a loss of significance in the characteristics of breast/body weight and lower inner quadrant, in line with the plots (Fig. 6b). The cutoffs computed without outliers were of comparable magnitude, depth ratio $>1.5, \Delta$ depth $>23 \mathrm{~mm}$, depth prone $>62 \mathrm{~mm}$, breast volume left $>197 \mathrm{~mL}$, and right $>193 \mathrm{~mL}$.

The post-dosimetry penalty scores were significant predictors of the dosimetric gain (Table 2). These simulate the situation of only one treatment plan when either the prone or the supine setup is available. If the prone penalty score is already $<2.4$, changing to the supine setup is unlikely to further reduce the score. Conversely, if the supine penalty score is $>2.1$, changing to the prone setup has a good likelihood of reducing the penalty, as inferred earlier from the inspection of the bullet-arrow chart (Fig. 5).

\section{Discussion}

Dosimetric gain analysis in this patient population that included breast volumes as small as $34 \mathrm{~mL}$ and two breast implant patients demonstrated a preponderant advantage of the prone setup as compared with the supine setup. The benefit of the prone setup was observed in $62.1 \%$ of the cases.

Our results confirm the general strong benefit of prone positioning on lung dose [29], which was reduced from $7.6 \%$ of the prescribed dose in supine position to $1.9 \%$ in prone, and the benefit of DiBH with regard to the mean heart dose $[22,23]$, which was reduced from $3.4 \%$ prone to $1.9 \%$ supine.

The idea to predict the benefit of prone position instead of dual planning is not new. Zhao et al.'s support vector machine selected heart orientation, heart-tumor distance, and in-field lung volume as the best features to reduce the proportion of prone-treated patients who would have required a second supine CT [51]. They drew attention to the (unmet) need to determine the plasticity of deformation and displacement of organs between the two positions. Lymberis et al. reported that $46 / 53(87 \%)$ cases of left breast cancer were best treated prone, in all with breast volumes $>1500 \mathrm{cc}$, 
Table 2 Robust linear regression analysis of the penalty difference prone - supine

\begin{tabular}{|c|c|c|c|c|c|}
\hline Characteristics & Intercept & Coefficient & SD & Range prone better & Unit \\
\hline \multicolumn{6}{|l|}{$\overline{\text { PRE-DOSIMETRY }}$} \\
\hline \multicolumn{6}{|l|}{ Pendulousness } \\
\hline Breast depth ratio prone/supine ${ }^{a}$ & 1.244 & -0.7950 & 0.2493 & $>1.6$ & Ratio \\
\hline Breast $\Delta$ depth difference prone - supine ${ }^{\mathrm{a}}$ & 0.338 & -0.0111 & 0.0033 & $>\mathbf{3 1}$ & $\mathbf{m m}$ \\
\hline Breast depth prone & 0.444 & -0.0057 & 0.0020 & $>77$ & $\mathbf{m m}$ \\
\hline \multicolumn{6}{|l|}{ Breast/body } \\
\hline Breast volume/body weight ratio & 0.278 & -0.0564 & 0.0273 & $>4.9$ & $\mathrm{~mL} / \mathrm{kg}$ \\
\hline \multicolumn{6}{|l|}{ Tumor location } \\
\hline Lower inner quadrant (LIQ) vs. not LIQ & -0.176 & 2.7829 & 0.5075 & Not LIQ & Binary \\
\hline \multicolumn{6}{|l|}{ Breast size } \\
\hline Left breast volume supine & 0.207 & -0.0007 & 0.0003 & $>282$ & $\mathbf{m L}$ \\
\hline Right breast volume supine $\mathrm{a}^{\mathrm{a}}$ & 0.177 & -0.0005 & 0.0002 & $>\mathbf{3 4 7}$ & $\mathbf{m L}$ \\
\hline Breast depth supine & 0.278 & -0.0073 & 0.0038 & $>38$ & $\mathrm{~mm}$ \\
\hline \multicolumn{6}{|l|}{ Body size } \\
\hline Weight & 0.474 & -0.0087 & 0.0046 & $>54$ & $\mathrm{~kg}$ \\
\hline Body mass index & 0.156 & -0.0115 & 0.0143 & $>14$ & $\mathrm{~kg} / \mathrm{m}^{2}$ \\
\hline Heart volume supine & 0.217 & -0.0008 & 0.0008 & $>263$ & $\mathrm{~mL}$ \\
\hline Height & 3.029 & -0.0193 & 0.0118 & $>157$ & $\mathrm{~cm}$ \\
\hline \multicolumn{6}{|l|}{ Deep inspiration breath-hold (DiBH) capability } \\
\hline Right lung volume supine & -0.708 & 0.2071 & 0.1484 & $<3.4$ & $\mathrm{~L}$ \\
\hline Total lung volume supine & -0.640 & 0.0970 & 0.0766 & $<6.6$ & $\mathrm{~L}$ \\
\hline Left lung volume supine & -0.537 & 0.1641 & 0.1542 & $<3.3$ & $\mathrm{~L}$ \\
\hline Age & 0.261 & -0.0074 & 0.0064 & $>35$ & Years \\
\hline LAD-chest wall distance & -0.005 & -0.0056 & 0.0102 & NI & $\mathrm{mm}$ \\
\hline \multicolumn{6}{|l|}{ Other } \\
\hline Couch type Varian vs. Bionix & -0.124 & -0.2865 & 0.1868 & NI & Binary \\
\hline Preference prone vs. else & -0.130 & -0.0437 & 0.1785 & NI & Binary \\
\hline \multicolumn{6}{|l|}{ POST-DOSIMETRY } \\
\hline Prone penalty score & -2.134 & 0.8961 & 0.0389 & $<2.4$ & $\%$ dose \\
\hline Supine penalty score & 1.464 & -0.7004 & 0.1008 & $>2.1$ & $\%$ dose \\
\hline
\end{tabular}

Significant characteristics (lcoefficient/SDI >1.96) are highlighted in bold

$S D$ standard deviation of the coefficients, $N I$ : cutoff not identifiable

${ }^{a}$ The cutoffs using nonlinear transforms were as follows: ratio: $1.7 ; \Delta$ depth: $35 \mathrm{~mm}$; right breast volume: $543 \mathrm{~mL}$

in $95 \%$ with $750-1500 \mathrm{cc}$, and in $68 \%$ with $<750 \mathrm{cc}$ [52]. In a study of 138 left breast cancers, Varga et al. established a model based on BMI, median distance between LAD and the chest wall, and heart area included in the radiation field on a single supine CT slice as the most appropriate predictor for the choice of positioning [31]. Kahan et al. confirmed the utility of the model, the treatment position was prone in $67 / 100(67 \%)$ and $47 / 60(78.3 \%)$ patients of a validation and a clinical practice series, respectively [53]. Rarosi et al. analyzed the predictive performance of different statistical models of BMI, LAD distance, and in-field heart area on the LAD mean dose difference between supine and prone position [54]. Multiple linear regression appeared to be the most useful model.

The present study is novel as the previous benefit predictions compared prone setup to a free breathing, not a DiBH supine setup. Our approach also differs. We de- fined a penalty score taking into account all structures, reducing the question of a benefit to a single number which is easy to compare. Furthermore, in some previous publications only heart doses were considered although dose sparing in the lung can indeed be very important [55].

However, the approach has drawbacks. The "type 1" weights of heart, lungs, breasts, and tumor bed reflected a single institution's choice. Weights may need to be defined according to probability and severeness of side effects in the different targets or organs at risk. The importance of lung, heart, and breast dose is not the same for each patient. To select patients for prone or supine setup, individual risks need to be considered [56].

These are key issues. Therefore, we expand the analysis in this discussion. Instead of the "type 1" penalty score, alternative organ-specific (or side effect-specific) scores were evaluated. Table 3 lists alternative sets of weights accord- 
Table 3 Alternative sets of penalty weights

\begin{tabular}{llllllll}
\hline $\begin{array}{l}\text { Priority } \\
\text { type }\end{array}$ & Weights & \multicolumn{7}{l}{} & & \\
\cline { 2 - 7 } & Heart & Right lung & Left lung & Tumor bed & Left breast & Right breast & Body \\
\hline Type 1 & 0.40 & 0.16 & 0.14 & 0.11 & 0.09 & 0.10 & 0 \\
Heart & 0.65 & 0.08 & 0.07 & 0.10 & 0.05 & 0.05 & 0.04 \\
Lungs & 0.20 & 0.30 & 0.35 & 0.07 & 0.04 & 0.05 & 0 \\
PTVs & 0.15 & 0.08 & 0.07 & 0.35 & 0.30 & 0.15 & 0.30 \\
Body & 0.10 & 0.15 & 0.15 & 0.08 & 0.07 & 0 \\
\hline
\end{tabular}

PTVs planning target volumes

Italicized values highlight which organ or group of organs receive the highest weights according to the priority type; in each row the sum of these values equals at least 0.65

Table 4 Penalty scores according to setup and type of priority

\begin{tabular}{|c|c|c|c|}
\hline \multirow[t]{2}{*}{$\begin{array}{l}\text { Priority } \\
\text { type }\end{array}$} & \multicolumn{2}{|c|}{$\begin{array}{l}\text { Penalty score } \\
\text { Median (range) } \\
\end{array}$} & \multirow[t]{2}{*}{$\begin{array}{l}\Delta \text { penalty prone - supine } \\
\text { Median (range) }\end{array}$} \\
\hline & Supine & Prone & \\
\hline Type 1 & $\begin{array}{l}2.36 \\
(1.33-4.26)\end{array}$ & $\begin{array}{l}2.14 \\
(0.98-10.78)\end{array}$ & $\begin{array}{l}-0.21 \\
(-2.47-7.24)\end{array}$ \\
\hline Heart & $\begin{array}{l}2.11 \\
(1.26-3.89)\end{array}$ & $\begin{array}{l}2.41 \\
(1.17-14.13)\end{array}$ & $\begin{array}{l}0.41 \\
(-1.78-11.3)\end{array}$ \\
\hline Lungs & $\begin{array}{l}3.39 \\
(1.37-5.91)\end{array}$ & $\begin{array}{l}1.66 \\
(0.68-8.01)\end{array}$ & $\begin{array}{l}-1.64 \\
(-4.26-3.43)\end{array}$ \\
\hline PTVs & $\begin{array}{l}2.19 \\
(1.37-4.92)\end{array}$ & $\begin{array}{l}2.19 \\
(1.05-10.16)\end{array}$ & $\begin{array}{l}0.01 \\
(-3.25-7.19)\end{array}$ \\
\hline Body & $\begin{array}{l}3.79 \\
(2.07-6.33)\end{array}$ & $\begin{array}{l}3.08 \\
(1.57-7.66)\end{array}$ & $\begin{array}{l}-0.63 \\
(-3.29-3.41)\end{array}$ \\
\hline
\end{tabular}

$P T V$ planning target volume. Penalty score's units as percent of prescribed dose $\Delta$ penalty computed from all individual penalty prone minus penalty supine ing to four broad categories of patients' clinical conditions. The heart priority type would represent patients with history of heart disease, presenting cardiovascular comorbidity, or receiving cardiotoxic therapy such as doxorubicin or trastuzumab, thus requiring most heart protection [27]. The lungs priority type would apply to patients with higher age or a history of pulmonary disease $[9,57]$. The $P T V s$ priority type would be patients at a high risk of local relapse, such as large tumors or negative hormone receptor status [58]. The body priority type might be patients in whom radiationinduced cancer is a concern, for whom precedence might be given to avoid irradiation of large volumes of tissues $[25,59,60]$ as well as avoiding high doses [61]. The DVH of the whole-length CT body structure, or external contour, was exported with the other DVHs. The body structure includes organs and PTVs. Using it in a penalty score would doubly penalize the OARs and PTVs. Hence its 0 weight in the preceding priority types; but here the body structure is relevant to assess how the risk of second cancer can affect the role of the prone setup.

Table 4 summarizes the penalty scores in prone and supine computed according to the priority types defined in Table 3. As might be expected, heart priority increases prone penalty $(\Delta$ penalty $=0.41)$, while lungs priority decreases prone penalty $(\Delta$ penalty $=-1.64)$. Prone and supine are balanced with $P T V s$ priority $(\Delta$ penalty $=0.01)$. Prone penalty decreases with body priority $(\Delta$ penalty $=-0.63)$, which suggests that prone might have a lower risk of second cancer as compared with supine. That latter observation brings to the forefront an earlier phantom dose measurement study that called attention to the larger doses received by far distant organs-notably the eyes, ovaries, cervical, thoracic, and lumbar vertebrae-with supine tangential fields as compared with prone tangential fields [62]. Other authors also observed that the dose to nontarget areas (hotspots outside the breast PTV and other than lung or heart, such as the latissimus dorsi) was consistently reduced in the prone position [63, 64].

Fig. 7 compares the prone penalty percent change relative to supine penalty according to the priority types. The number of patients in whom prone reduced the penalty ranged from 27 to 109 of 116 . The proportion of patients was lowest but still substantial with heart priority, $23.3 \%$ (95\% CI: $15.9 \%, 32.0 \%$ ) and highest with lungs priority, $94.0 \%$ (95\% CI: $88.0 \%, 97.5 \%)$. The type 1 priority appeared to be a fair representative average.

The outcomes show that the penalty score can be transparently adapted. Different penalty types hint at the possibility to tailor radiotherapy prescription according to a patient's pathology. Regression might find different predictors 
Fig. 7 Prone penalty percent change from supine penalty, according to priority type. PTV planning target volumes. Priority types defined in Table 3

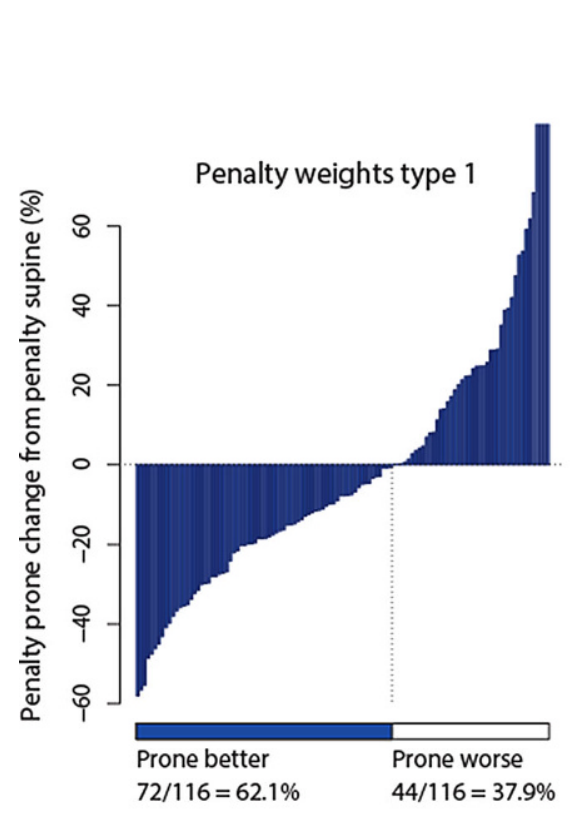

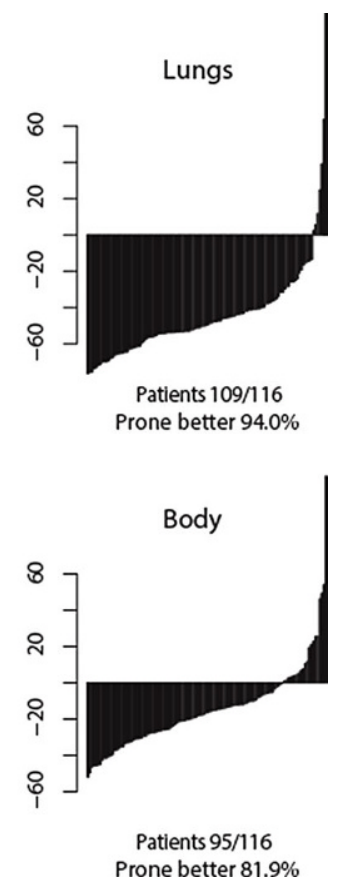

but would best be investigated in a multi-institutional study. For the remainder of the discussion, we focus only on the type 1 priority.

Pendulousness or plasticity were the foremost predictors of a dosimetric gain (reduction of penalty score priority type 1). The breast air-to-surface ratio has been proposed as a measure of pendulousness for use with automatic segmentation [65]. The present study proposes other measures-the breast depth prone/supine ratio and breast prone - supine $\Delta$ depth difference [66]. Both can be assessed clinically. Examining the patient lying supine followed by a standing position and leaning forward $90^{\circ}$ might provide an indication of how much the breast sags from the chest wall, thus helping to select the most favorable position for the planning CT. Among the 3 patients with extreme prone penalty scores (cases 187, 136, and 11, Fig. 5), the breast depth ratios were $1.3,1.5$, and 1.2 , and the breast $\Delta$ depths were 15 , 19 , and $11 \mathrm{~mm}$, respectively. Case 11 had a breast implant, case 136 had a lower inner quadrant tumor, and case 187 had a scar that appeared to hinder the breast's displacement (Fig. 1). Applying the pendulousness assessment just mentioned, they would most likely not have been selected for a prone setup.

Several pitfalls are worth underscoring. Indeed, the mean absolute dose deviation is a new metric that has been conceived to implement the present analysis [43]. Weighted penalty scoring and dosimetric gain analyses are uncharted territories. We have already expanded on the impact of weights on the gains. Choosing penalty score weightings may require a multi-institutional consensus if the present methodology has to be widely adopted in the future. The treatment delivery relied on 3D dose distributions which were not reviewed. A dose distribution assessment of the LAD, either prone or supine, was dismissed as it was not part of our standard contouring policy at the time the study was undertaken. The study was retrospective and subject to selection biases. Few women were at the lower and higher ranges of the breast volume and weights, thus potentially yielding unreliable cutoff estimates. The analyses were not designed for validation.

Strengths are also worth mentioning, most especially the perspective of a new dosimetric paradigm. The MADDs can be extracted from dose-volume histograms; dosimetric data can be analyzed even when the original treatment planning files are no longer available. The penalty scores provide a quantitative parameter to streamline the ranking of treatment plans. The weights can be adapted to the patient's pathology as discussed earlier (Tables 3and 4, Fig. 7). Although the LAD dose distribution was not available, it has been shown to correlate with the mean heart dose, with $R=0.87$ in both setups [54]. Moreover, our "priority type 1" penalty score gave the highest priority to the heart. Every patient underwent dual CT planning, providing a good balance of patients' characteristics to compare prone with supine setups. Although data were collected retrospectively, all treatment plans were created prospectively, aiming to select the best setup in an individualized manner.

Last but not least, any treatment decision implies tradeoffs between organs at risk and target coverage [18]. As recently suggested by other research groups, implementing DiBH in prone setup conditions might represent an even better solution, potentially providing the best for both heart 
and lung sparing $[67,68]$. Another improvement might be the use of breast cups for prone [26, 69], which one of the authors is currently investigating. While waiting for validation studies of new techniques, the present results can help to better select patients for prone or supine treatment.

\section{Conclusion}

A dosimetric gain was associated with a prone setup in $62.1 \%$ of patients. Measures of breast pendulousness or plasticity, breast depth ratio, or breast depth difference were the most significant predictors of gain. Pending a prospective evaluation, these measures might help to identify which treatment position, either prone or supine, could be most advantageous.

Acknowledgements Heartfelt thanks to Yung-Eae Lee Santana De Alcantara for the protocols' implementation, to Henri Delorme who developed Pulmetro and made it possible to start with DiBH, to Frank Grozema who trained and brought back the NYU prone technique. All treatments were supervised by Vincent Vinh-Hung while he was attached to the Geneva University Hospitals. Our thanks to Dayleen De Riggs and AJE American Journal Experts for help with language editing. We are deeply indebted to our reviewers, a great part of the Discussion and the development beyond the study original intent owe to their insightful comments.

Part of the study was presented at the ASTRO's 62nd Annual Meeting October 25-28, 2020, poster \# 3777, title: Application of the Mean Absolute Dose Deviation to the Dosimetric Gain Analysis of Left Whole Breast Radiotherapy by Prone-Free Breathing versus Supine-Deep Inspiration Breath Hold (DiBH).

Author Contribution Concept: VVH. Design: VVH. Conduct: XW, OFB, GD, ML, MK. Supervision: VVH, RM. Data acquisition: VVH, XW, OFB, GD, ML, MK. Data verification: XW, VVH, GD. Data interpretation: XW, VVH, OFB, NPN, GD, OG, RM. Patient surveillance: VVH, XW, OFB, GD, ML, MK. Statistical analysis: VVH, OG. Critical review: OFB, GD, NPN, RM, OG. Literature search: VVH, GD. Manuscript drafting, editing: XW, OFB, GD, ML, MK, NPN, RM, OG, VVH. Revision and final approval: all authors.

Funding Open access funding provided by University of Geneva

\section{Compliance with ethical guidelines}

Conflict of interest N. P. Nguyen and V. Vinh-Hung have joint patents for the application of the mean absolute dose deviation, USPTO 62/608,751, WO/2019/014384. G. Dipasquale and Geneva University Hospitals have a patent pending for a prone immobilization device, EP18 206 344.6, 52146/WO. R. Miralbell had research grants from BrainLab and from Varian AG. V. Vinh-Hung had contact with Varian Medical Systems in 2012-2013 for the installation of Varian Pivotal Prone Breast Care at the Radiation Oncology department of the Geneva University Hospitals, Switzerland. The Radiation Oncology Department of the Geneva University Hospitals had a research agreement with Varian Medical Systems. The department received research funding from the Fundació Privada CELLEX. X. Wang, O. FargierBochaton, M. Laouiti, M. Kountouri, and O. Gorobets declare that they have no competing interests.
Ethical standards All procedures performed in studies involving human participants or on human tissue were in accordance with the ethical standards of the institutional and/or national research committee and with the 1975 Helsinki declaration and its later amendments or comparable ethical standards. The study received approval at the Geneva University Hospitals Institutional Review Board. Informed consent: not applicable; patients signed informed consent to the treatment procedure, but the study was retrospective.

Open Access This article is licensed under a Creative Commons Attribution 4.0 International License, which permits use, sharing, adaptation, distribution and reproduction in any medium or format, as long as you give appropriate credit to the original author(s) and the source, provide a link to the Creative Commons licence, and indicate if changes were made. The images or other third party material in this article are included in the article's Creative Commons licence, unless indicated otherwise in a credit line to the material. If material is not included in the article's Creative Commons licence and your intended use is not permitted by statutory regulation or exceeds the permitted use, you will need to obtain permission directly from the copyright holder. To view a copy of this licence, visit http://creativecommons.org/licenses/by/4. $0 /$.

\section{References}

1. Bray F, Ferlay J, Soerjomataram I, Siegel RL, Torre LA, Jemal A (2018) Global cancer statistics 2018: GLOBOCAN estimates of incidence and mortality worldwide for 36 cancers in 185 countries. CA Cancer J Clin 68(6):394-424. https://doi.org/10.3322/caac. 21492

2. DeSantis CE, Ma J, Gaudet MM, Newman LA, Miller KD, Goding Sauer A, Jemal A, Siegel RL (2019) Breast cancer statistics, 2019. CA Cancer J Clin 69(6):438-451. https://doi.org/10.3322/ caac. 21583

3. Allemani C, Matsuda T, Di Carlo V, Harewood R, Matz M, Niksic M, Bonaventure A, Valkov M, Johnson CJ, Esteve J, Ogunbiyi OJ, Azevedo ESG, Chen WQ, Eser S, Engholm G, Stiller CA, Monnereau A, Woods RR, Visser O, Lim GH, Aitken J, Weir HK, Coleman MP, Group CW (2018) Global surveillance of trends in cancer survival 2000-14 (CONCORD-3): analysis of individual records for 37513025 patients diagnosed with one of 18 cancers from 322 population-based registries in 71 countries. Lancet 391(10125):1023-1075. https://doi.org/10.1016/S01406736(17)33326-3

4. Vinh-Hung V, Verschraegen C, The Breast Conserving Surgery Project (2004) Breast-conserving surgery with or without radiotherapy: pooled-analysis for risks of ipsilateral breast tumor recurrence and mortality. J Natl Cancer Inst 96(2):115-121. https://doi.org/10. 1093/jnci/djh246

5. Cuzick J, Stewart H, Peto R, Baum M, Fisher B, Host H, Lythgoe JP, Ribeiro G, Scheurlen H, Wallgren A (1987) Overview of randomized trials of postoperative adjuvant radiotherapy in breast cancer. Cancer Treat Rep 71(1):15-29

6. Cuzick J, Stewart H, Rutqvist L, Houghton J, Edwards R, Redmond C, Peto R, Baum M, Fisher B, Host H (1994) Cause-specific mortality in long-term survivors of breast cancer who participated in trials of radiotherapy. J Clin Oncol 12(3):447-453

7. Van de Steene J, Soete G, Storme G (2000) Adjuvant radiotherapy for breast cancer significantly improves overall survival: the missing link. Radiother Oncol 55(3):263-272

8. Van de Steene J, Vinh-Hung V, Cutuli B, Storme G (2004) Adjuvant radiotherapy for breast cancer: effects of longer follow-up. Radiother Oncol 72(1):35-43

9. Dorr W, Bertmann S, Herrmann T (2005) Radiation induced lung reactions in breast cancer therapy. Modulating factors and conse- 
quential effects. Strahlenther Onkol 181(9):567-573. https://doi. org/10.1007/s00066-005-1457-9

10. Verschraegen C, Vinh-Hung V (2006) Effects of radiotherapy and surgery for early breast cancer. Lancet 367(9523):1654-1654. https://doi.org/10.1016/s0140-6736(06)68726-6

11. Vinh-Hung V, Truong PT, Janni W, Nguyen NP, Vlastos G, Cserni G, Royce ME, Woodward WA, Promish D, Tai P, Soete G, Balmer-Majno S, Cutuli B, Storme G, Bouchardy C (2009) The effect of adjuvant radiotherapy on mortality differs according to primary tumor location in women with node-positive breast cancer. Strahlenther Onkol 185(3):161-168. https://doi.org/10.1007/ s00066-009-1921-z

12. Bouchardy C, Rapiti E, Usel M, Majno SB, Vlastos G, Benhamou S, Miralbell R, Neyroud-Caspar I, Verkooijen HM, VinhHung V (2010) Excess of cardiovascular mortality among nodenegative breast cancer patients irradiated for inner-quadrant tumors. Ann Oncol 21(3):459-465

13. Verbanck S, Hanon S, Schuermans D, Van Parijs H, Vinh-Hung V, Miedema G, Verellen D, Storme G, Fontaine C, Lamote J, De Ridder M, Vincken W (2016) Mild lung restriction in breast cancer patients after Hypofractionated and conventional radiation therapy: a 3-year follow-up. Int J Radiat Oncol Biol Phys 95(3):937-945. https://doi.org/10.1016/j.ijrobp.2016.02.008

14. Killander F, Wieslander E, Karlsson P, Holmberg E, Lundstedt D, Holmberg L, Werner L, Koul S, Haghanegi M, Kjellen E, Nilsson P, Malmstrom P (2020) No increased cardiac mortality or morbidity of radiation therapy in breast cancer patients after breast-conserving surgery: 20-year follow-up of the randomized SweBCGRT trial. Int J Radiat Oncol Biol Phys 107(4):701-709. https://doi.org/10.1016/ j.ijrobp.2020.04.003

15. Lomax AJ, Cella L, Weber D, Kurtz JM, Miralbell R (2003) Potential role of intensity-modulated photons and protons in the treatment of the breast and regional nodes. Int J Radiat Oncol Biol Phys 55(3):785-792. https://doi.org/10.1016/s0360-3016(02)04210-4

16. Sautter-Bihl ML, Budach W, Dunst J, Feyer P, Haase W, Harms W, Sedlmayer F, Souchon R, Wenz F, Sauer R (2007) DEGRO practical guidelines for radiotherapy of breast cancer I: breast-conserving therapy. Strahlenther Onkol 183(12):661-666

17. Toscas JI, Linero D, Rubio I, Hidalgo A, Arnalte R, Escude L, Cozzi L, Fogliata A, Miralbell R (2010) Boosting the tumor bed from deep-seated tumors in early-stage breast cancer: a planning study between electron, photon, and proton beams. Radiother Oncol 96(2):192-198. https://doi.org/10.1016/j.radonc.2010.05.007

18. Fogliata A, Seppala J, Reggiori G, Lobefalo F, Palumbo V, De Rose F, Franceschini D, Scorsetti M, Cozzi L (2017) Dosimetric trade-offs in breast treatment with VMAT technique. Br J Radiol 90(1070):20160701. https://doi.org/10.1259/bjr.20160701

19. Abo-Madyan Y, Welzel G, Sperk E, Neumaier C, Keller A, Clausen S, Schneider F, Ehmann M, Sutterlin M, Wenz F (2019) Single-center long-term results from the randomized phase-3 TARGIT-A trial comparing intraoperative and whole-breast radiation therapy for early breast cancer. Strahlenther Onkol 195(7):640647. https://doi.org/10.1007/s00066-019-01438-5

20. Strnad V, Krug D, Sedlmayer F, Piroth MD, Budach W, Baumann R, Feyer P, Duma MN, Haase W, Harms W, Hehr T, Fietkau R, Dunst J, Sauer R, Breast Cancer Expert Panel of the German Society of Radiation O (2020) DEGRO practical guideline for partial-breast irradiation. Strahlenther Onkol 196(9):749-763. https://doi.org/10.1007/s00066-020-01613-z

21. Lemanski C, Thariat J, Ampil FL, Bose S, Vock J, Davis R, Chi A, Dutta S, Woods W, Desai A, Godinez J, Karlsson U, Mills M, Nguyen NP, Vinh-Hung V, International Geriatric Radiotherapy G (2014) Image-guided radiotherapy for cardiac sparing in patients with left-sided breast cancer. Front Oncol 4:257-257. https://doi. org/10.3389/fonc.2014.00257
22. Hepp R, Ammerpohl M, Morgenstern C, Nielinger L, Erichsen P, Abdallah A, Galalae R (2015) Deep inspiration breath-hold (DIBH) radiotherapy in left-sided breast cancer: dosimetrical comparison and clinical feasibility in 20 patients. Strahlenther Onkol 191(9):710-716. https://doi.org/10.1007/s00066-015-0838-y

23. Schonecker S, Heinz C, Sohn M, Haimerl W, Corradini S, Pazos M, Belka C, Scheithauer H (2016) Reduction of cardiac and coronary artery doses in irradiation of left-sided breast cancer during inspiration breath hold : a planning study. Strahlenther Onkol 192(11):750-758. https://doi.org/10.1007/s00066-016-1039-z

24. Sakka M, Kunzelmann L, Metzger M, Grabenbauer GG (2017) Cardiac dose-sparing effects of deep-inspiration breath-hold in left breast irradiation : Is IMRT more beneficial than VMAT? Strahlenther Onkol 193(10):800-811. https://doi.org/10.1007/s00066-017$1167-0$

25. Corradini S, Ballhausen H, Weingandt H, Freislederer P, Schonecker S, Niyazi M, Simonetto C, Eidemuller M, Ganswindt U, Belka C (2018) Left-sided breast cancer and risks of secondary lung cancer and ischemic heart disease : effects of modern radiotherapy techniques. Strahlenther Onkol 194(3):196-205. https:// doi.org/10.1007/s00066-017-1213-y

26. Duma MN, Baumann R, Budach W, Dunst J, Feyer P, Fietkau R, Haase W, Harms W, Hehr T, Krug D, Piroth MD, Sedlmayer F, Souchon R, Sauer R, Breast Cancer Expert Panel of the German Society of Radiation O (2019) Heart-sparing radiotherapy techniques in breast cancer patients: a recommendation of the breast cancer expert panel of the German society of radiation oncology (DEGRO). Strahlenther Onkol 195(10):861-871. https://doi.org/ 10.1007/s00066-019-01495-w

27. Piroth MD, Baumann R, Budach W, Dunst J, Feyer P, Fietkau R, Haase W, Harms W, Hehr T, Krug D, Roser A, Sedlmayer F, Souchon R, Wenz F, Sauer R (2019) Heart toxicity from breast cancer radiotherapy : current findings, assessment, and prevention. Strahlenther Onkol 195(1):1-12. https://doi.org/10.1007/s00066018-1378-z

28. Heymann S, Dipasquale G, Nguyen NP, San M, Gorobets O, Leduc N, Verellen D, Storme G, Van Parijs H, De Ridder M, VinhHung V (2020) Two-level factorial pre-tomobreast pilot study of tomotherapy and conventional radiotherapy in breast cancer: post hoc utility of a mean absolute dose deviation penalty score. Technol Cancer Res Treat 19:1533033820947759. https://doi.org/10.1177/ 1533033820947759

29. Huppert N, Jozsef G, DeWyngaert K, Formenti SC (2011) The role of a prone setup in breast radiation therapy. Front Oncol 1(31):1-8

30. Würschmidt F, Stoltenberg S, Kretschmer M, Petersen C (2014) Incidental dose to coronary arteries is higher in prone than in supine whole breast irradiation A dosimetric comparison in adjuvant radiotherapy of early stage breast cancer. Strahlenther Onkol 190(6):563-568. https://doi.org/10.1007/s00066-014-0606-4

31. Varga Z, Cserhati A, Rarosi F, Boda K, Gulyas G, Egyued Z, Kahan $Z$ (2014) Individualized positioning for maximum heart protection during breast irradiation. Acta Oncol 53(1):58-64. https://doi. org/10.3109/0284186x.2013.781674

32. Blank E, Willich N, Fietkau R, Popp W, Schaller-Steiner J, Sack H, Wenz F (2012) Evaluation of time, attendance of medical staff, and resources during radiotherapy for breast cancer patients. The DEGRO-QUIRO trial. Strahlenther Onkol 188(2):113-119. https:// doi.org/10.1007/s00066-011-0020-0

33. Sack C, Sack H, Willich N, Popp W (2015) Evaluation of the time required for overhead tasks performed by physicians, medical physicists, and technicians in radiation oncology institutions: the DEGRO-QUIRO study. Strahlenther Onkol 191(2):113-124. https://doi.org/10.1007/s00066-014-0758-2

34. Andrianarison VA, Laouiti M, Fargier-Bochaton O, Dipasquale G, Wang X, Nguyen NP, Miralbell R, Vinh-Hung V (2018) Contouring 
workload in adjuvant breast cancer radiotherapy. Cancer Radiother 22(8):747-753. https://doi.org/10.1016/j.canrad.2018.01.008

35. Delorme H (2007) Creation of the thoracic plethysmography. Strahlenther Onkol 183:186-186. https://doi.org/10.1007/s00066007-1002-0

36. Vinh-Hung V, Grozema F, Lee YE, Frangin I, Fargier-Bochaton O, Delorme H (2011) Single institution review of setup errors with deep-inspiration breath hold (DIBH) for left sided breast RT. Abstract 41. Strahlenther Onkol 187(8):525-525. https://doi.org/10. 1007/s00066-011-1002-y

37. Lee G, Delorme H, Grozema FI, Orsel K, Rossi S, Mary-Bruttin M, Fargier-Bochaton O, Vinh-Hung V (2011) Patients' symptom assessment at prone and supine simulation for breast RT. Strahlenther Onkol 187(8):525-525. https://doi.org/10.1007/s00066-011-1002y

38. Caparrotti F, Monnier S, Fargier-Bochaton O, Laouiti M, Caparrotti P, Peguret N, Vlastos G, Nguyen NP, Vinh-Hung V (2012) Incidence of skin recurrence after breast cancer surgery. Radiother Oncol 103(2):275-277. https://doi.org/10.1016/j.radonc.2011.12. 019

39. Feng M, Moran JM, Koelling T, Chughtai A, Chan JL, Freedman L, Hayman JA, Jagsi R, Jolly S, Larouere J, Soriano J, Marsh R, Pierce LJ (2011) Development and validation of a heart atlas to study cardiac exposure to radiation following treatment for breast cancer. Int J Radiat Oncol Biol Phys 79(1):10-18. https://doi.org/ 10.1016/j.ijrobp.2009.10.058

40. Vock J, Peguret N, Balmer-Majno S, Miralbell R, Vinh-Hung V, Schneider D (2010) Four times weekly adjuvant breast radiotherapy with a moderately intensified boost to the tumour bed-feasibility and acute toxicity. Abstract 254. Ejc Suppl 8(3):132-133. https:// doi.org/10.1016/s1359-6349(10)70280-9

41. Buwenge M, Cammelli S, Ammendolia I, Tolento G, Zamagni A, Arcelli A, Macchia G, Deodato F, Cilla S, Morganti AG (2017) Intensity modulated radiation therapy for breast cancer: current perspectives. Breast Cancer 9:121-126. https://doi.org/10.2147/BCTT. S113025

42. Raj KA, Evans ES, Prosnitz RG, Quaranta BP, Hardenbergh PH, Hollis DR, Light KL, Marks LB (2006) Is there an increased risk of local recurrence under the heart block in patients with left-sided breast cancer? Cancer J 12(4):309-317

43. Vinh-Hung V, Leduc N, Verellen D, Verschraegen C, Dipasquale G, Nguyen NP (2020) The mean absolute dose deviation-a common metric for the evaluation of dose-volume histograms in radiation therapy. Med Dosim 45(2):186-189. https://doi.org/10.1016/j. meddos.2019.10.004

44. Student (1908) The probable error of a mean. Biometrika 6(1):1-25. https://doi.org/10.1093/biomet/6.1.1

45. Clopper CJ, Pearson ES (1934) The use of confidence or fiducial limits illustrated in the case of the binomial. Biometrika 26(4):404-413. https://doi.org/10.1093/biomet/26.4.404

46. Sauerbrei W, Meier-Hirmer C, Benner A, Royston P (2006) Multivariable regression model building by using fractional polynomials: description of SAS, STATA and R programs. Comput Stat Data Anal 50(12):3464-3485. https://doi.org/10.1016/j.csda.2005. 07.015

47. Venables WN, Ripley BD (2002) Modern applied statistics with S, 4 th edn. Statistics and Computing. Springer, New York

48. Smucker B, Krzywinski M, Altman N (2019) Two-level factorial experiments. Nat Methods 16(3):211-212. https://doi.org/10.1038/ s41592-019-0335-9

49. R Core Team (2020) R: a language and environment for statistical computing. $\mathrm{R}$ foundation for statistical computing $\mathrm{R}$ version 3.6.3

50. Wickham H (2016) ggplot2: elegant graphics for data analysis. Use R! Springer, Cham https://doi.org/10.1007/978-3-319-24277-4

51. Zhao X, Wong EK, Wang Y, Lymberis S, Wen B, Formenti S, Chang J (2010) A support vector machine (SVM) for predicting preferred treatment position in radiotherapy of patients with breast cancer. Med Phys 37(10):5341-5350. https://doi.org/10.1118/1. 3483264

52. Lymberis SC, deWyngaert JK, Parhar P, Chhabra AM, Fenton-Kerimian M, Chang J, Hochman T, Guth A, Roses D, Goldberg JD, Formenti SC (2012) Prospective assessment of optimal individual position (prone versus supine) for breast radiotherapy: volumetric and dosimetric correlations in 100 patients. Int J Radiat Oncol Biol Phys 84(4):902-909. https://doi.org/10.1016/j.ijrobp.2012.01.040

53. Kahan Z, Rarosi F, Gaal S, Cserhati A, Boda K, Darazs B, Koszo R, Lakosi F, Gulyban A, Coucke PA, Varga Z (2018) A simple clinical method for predicting the benefit of prone vs. supine positioning in reducing heart exposure during left breast radiotherapy. Radiother Oncol 126(3):487-492. https://doi.org/10.1016/j.radonc.2017. 12.021

54. Rarosi F, Boda K, Kahan Z, Varga Z (2019) Decision curve analysis apropos of choice of preferable treatment positioning during breast irradiation. BMC Med Inform Decis Mak 19(1):204. https:// doi.org/10.1186/s12911-019-0927-4

55. Taylor C, Correa C, Duane FK, Aznar MC, Anderson SJ, Bergh J, Dodwell D, Ewertz M, Gray R, Jagsi R, Pierce L, Pritchard KI, Swain S, Wang Z, Wang Y, Whelan T, Peto R, McGale P, Early Breast Cancer Trialists' Collaborative G (2017) Estimating the risks of breast cancer radiotherapy: evidence from modern radiation doses to the lungs and heart and from previous randomized trials. J Clin Oncol 35(15):1641-1649. https://doi.org/10.1200/ JCO.2016.72.0722

56. Dhami G, Zeng J, Vesselle HJ, Kinahan PE, Miyaoka RS, Patel SA, Rengan R, Bowen SR (2017) Framework for radiation pneumonitis risk stratification based on anatomic and perfused lung dosimetry. Strahlenther Onkol 193(5):410-418. https://doi.org/10.1007/ s00066-017-1114-0

57. Vasiljevic D, Arnold C, Neuman D, Fink K, Popovscaia M, Kvitsaridze I, Nevinny-Stickel M, Glatzer M, Lukas P, Seppi T (2018) Occurrence of pneumonitis following radiotherapy of breast cancer-A prospective study. Strahlenther Onkol 194(6):520-532. https://doi.org/10.1007/s00066-017-1257-z

58. Fastner G, Hauser-Kronberger C, Moder A, Reitsamer R, Zehentmayr F, Kopp P, Fussl C, Fischer T, Deutschmann H, Sedlmayer F (2016) Survival and local control rates of triple-negative breast cancer patients treated with boost-IOERT during breast-conserving surgery. Strahlenther Onkol 192(1):1-7. https://doi.org/10.1007/ s00066-015-0895-2

59. Simonetto C, Rennau H, Remmele J, Sebb S, Kundrat P, Eidemuller M, Wolf U, Hildebrandt G (2019) Exposure of remote organs and associated cancer risks from tangential and multifield breast cancer radiotherapy. Strahlenther Onkol 195(1):32-42. https://doi.org/10.1007/s00066-018-1384-1

60. Dorr W, Herrmann T (2002) Second primary tumors after radiotherapy for malignancies. Treatment-related parameters. Strahlenther Onkol 178(7):357-362. https://doi.org/10.1007/s00066-002-09516

61. Welte B, Suhr P, Bottke D, Bartkowiak D, Dorr W, Trott KR, Wiegel T (2010) Second malignancies in highdose areas of previous tumor radiotherapy. Strahlenther Onkol 186(3):174-179. https://doi.org/10.1007/s00066-010-2050-4

62. Bieri S, Russo M, Rouzaud M, Kurtz JM (1997) Influence of modifications in breast irradiation technique on dose outside the treatment volume. Int J Radiat Oncol Biol Phys 38(1):117-125. https:// doi.org/10.1016/s0360-3016(97)00278-2

63. Ramella S, Trodella L, Ippolito E, Fiore M, Cellini F, Stimato G, Gaudino D, Greco C, Ramponi S, Cammilluzzi E, Cesarini C, Piermattei A, Cesario A, D'Angelillo RM (2012) Whole-breast irradiation: a subgroup analysis of criteria to stratify for prone position treatment. Med Dosim 37(2):186-191. https://doi.org/10.1016/ j.meddos.2011.06.010 
64. Fernandez-Lizarbe E, Montero A, Polo A, Hernanz R, Moris R, Formenti S, Ramos A (2013) Pilot study of feasibility and dosimetric comparison of prone versus supine breast radiotherapy. Clin Transl Oncol 15(6):450-459. https://doi.org/10.1007/s12094-0120950-8

65. Dipasquale G, Wang X, Chatelain-Fontanella V, Vinh-Hung V, Miralbell R (2016) Automatic segmentation of breast in prone position: correlation of similarity indexes and breast pendulousness with dose/volume parameters. Radiother Oncol 120(1):124-127. https://doi.org/10.1016/j.radonc.2016.04.041

66. Chen JL-Y, Cheng JC-H, Kuo S-H, Chan H-M, Huang Y-S, Chen Y-H (2013) Prone breast forward intensity-modulated radiotherapy for Asian women with early left breast cancer: factors for cardiac sparing and clinical outcomes. J Radiat Res 54(5):899-908. https://doi.org/10.1093/jrr/rrt019
67. Mulliez T, Veldeman L, Speleers B, Mahjoubi K, Remouchamps V, Van Greveling A, Gilsoul M, Berwouts D, Lievens Y, Van den Broecke R, De Neve W (2015) Heart dose reduction by prone deep inspiration breath hold in left-sided breast irradiation. Radiother Oncol 114(1):79-84. https://doi.org/10.1016/j.radonc.2014.11.038

68. Saini AS, Das IJ, Hwang CS, Biagioli MC, Lee WE 3rd (2019) Biological indices evaluation of various treatment techniques for leftsided breast treatment. Pract Radiat Oncol 9(6):e579-e590. https:// doi.org/10.1016/j.prro.2019.06.020

69. Piroth MD, Petz D, Pinkawa M, Holy R, Eble MJ (2016) Usefulness of a thermoplastic breast bra for breast cancer radiotherapy : a prospective analysis. Strahlenther Onkol 192(9):609-616. https:// doi.org/10.1007/s00066-016-0981-0 